\title{
A Framework For The Life Cycle Management of Information Technology Projects: Projectit
}

\author{
Rodney A. Stewart
}

School of Engineering, Griffith University, Gold Coast Campus, Queensland, Australia

\section{ALL CORRESPONDENCE TO:}

Dr. Rodney A. Stewart

School of Engineering

Griffith University Gold Coast Campus

PMB 50 Gold Coast Mail Centre QLD 9726, Australia

Telephone: (+61 7) 55528778

Facsimile: (+61 7) 55528065

Email: r.stewart@griffith.edu.au 


\title{
A Framework For The Life Cycle Management of Information Technology Projects: Projectit
}

\begin{abstract}
As international competition continues to intensify, significant numbers of organisations are investing large amounts of resources into information and communication technologies as they seek to gain competitive advantage. Information Technology (IT) is increasingly being implemented for strategic reasons, so as to enable improved efficiency and to improve the control and productivity of internal processes. However, the failure of realising expected IT-induced benefits has led to a growing number of senior executives to question the value of IT investments. This research study was inspired by the perceived lack of a structured framework for the life cycle management of innovative IT projects (ProjectIT). Such a framework consists of three modules representing each phase of the IT project life cycle, namely, IT project selection (SelectIT), strategic IT implementation (ImplementIT) and IT performance evaluation (EvaluateIT). Moreover, industry practitioners require a user-friendly software tool to assist them to undertake this arduous task. This paper provides a description of each module of the ProjectIT framework and the current progress towards the development of the companion software package. ProjectIT should assist firms to rapidly select IT projects based on a range of monetary and non-monetary benefits and risks, implement these projects in a wellplanned strategic manner and evaluate the short- and long-term value generated from them.
\end{abstract}

Keywords: Information technology, Information systems, Life cycle management 


\section{Introduction}

Leading organisations use selection, implementation and evaluation processes uniformly at an enterprise level and within each business unit of their organisation. By contrast, there is very little or no uniformity in how risks, benefits, and costs of various IT projects are evaluated [1-3]. Moreover, many organisations appear to approach the whole management of IT in an unstructured or ad hoc manner throughout its life cycle $[4,5]$. Such approaches have evolved due to a limited understanding of the relationship between IT project implementation and traditional business performance metrics [6,7]. This relationship has been described as the 'productivity paradox' by some researchers in the field of IT project management [8]. The effective management of IT needs to be viewed as a structured iterative business process, which offers organisational learning from each phase of the IT project life cycle [5]. Undoubtedly, such an IT project life cycle framework (ProjectIT) should comprise three essential phases or modules: (1) IT project selection (SelectIT); (2) strategic IT implementation and monitoring (ImplementIT); and (3) IT performance evaluation (EvaluateIT). However, each phase should not be viewed as a separate step. Rather, each is conducted as part of a continual, interdependent management effort. Information gained from one phase is used to support activities in each of the other two phases. Fig. 1 illustrates the three phases, or modules, of the proposed IT project life cycle management process (ProjectIT).

It should be noted that the research foundations underpinning each module of the presented ProjectIT framework and companion software package, have been previously developed by the author, through a series of empirical or case study based research investigations and subsequently reported in the literature [5,7,914]. These previously developed module frameworks were originally applied to IT-based project information management platforms implemented in the construction industry. However, they have subsequently been modified to enable their generic application across all industry sectors. Therefore, the primary purpose of this paper is to present a whole-of-life IT project management framework which accumulates this existing body of knowledge but in an integrated and cohesive fashion. The following sections briefly describe each phase, or module, of the IT project life cycle framework (ProjectIT) and how they integrate with the next to provide a continual management process. 


\section{(INSERT FIGURE 1)}

Fig. 1. IT project life cycle management process (ProjectIT)

\section{IT project selection - SelectIT}

There have been numerous examples where IT projects have failed to meet expectations $[15,16]$. This is sometimes due to a lack of prior assessment of risks and returns before management commitment is made and funding approval is provided [17]. This failure to properly plan the implementation of IT investments generally results from a limited understanding of the relationship between IT investments and organisational performance [18]. Executives tend to lack the methods, skills and tools required for selecting a portfolio of IT projects and tools, which add the greatest value to their organisation [19]. A well-structured IT project selection phase helps ensure that an organisation selects those IT projects that will best support organisational needs and identifies and analyses an IT project's risks and proposed benefits before a significant amount of funds and resources are allocated. A critical aspect of this phase is management understanding and participation and the application of a structured decision-making process. Several methods have been proposed to help organisations make good IT project selection decisions [10,20,21]. However, many reported methods have several limitations and tend not to provide a means to combine tangible and intangible 'business value' and risk criteria. Others are too complex in structure and have little appeal to practitioners. To overcome the limitations of existing frameworks Stewart [5] suggest a five-step IT project selection process (SelectIT): Step 1: identify monetary and non-monetary factors; Step 2: define possibility distributions; Step 3: develop resultant aggregated possibility distribution; Step 4: combine resultant aggregated possibility distribution; and Step 5: rank IT projects. Fig. 2 illustrates each of these outlined steps and they are briefly described in the following sections. Size constraints of this paper limit the degree of explanation provided for each step. Readers are referred to Stewart [5] for a complete description of the SelectIT framework and its application in an industry setting. Moreover, readers should note that these steps are supported by the SelectIT module wizard of the ProjectIT software tool. 


\section{(INSERT FIGURE 2)}

Fig. 2. IT project selection module (SelectIT)

\subsection{SelectIT Step 1: Identify monetary and non-monetary factors}

In recent years, expenditures on IT have been significant. However, organisations fail to fully acknowledge the total costs of their IT projects. The total ownership costs of IT investments include both the direct and indirect costs. Typically, organisations encompass the direct costs as those attributed to the implementation and operation of the proposed IT project. Indirect costs comprise human and organisational factors. A significant amount of resource will also be used to investigate the potential of the IT project, and in experimenting with new information flows and modified reporting structures [18]. Wheatley [22] suggests that a further indirect human cost, which is often overlooked, is that of system support and trouble-shooting (i.e. IT project administration). According to Wheatley [22], lifetime support costs are at least $400 \%$ of the original purchase price. Total ownership costs include all direct and indirect costs that can be attributed with the initiation, design, development, operation and maintenance of the proposed IT project. Therefore, all costs for the proposed IT project, over its entire life cycle, must be included in the costing process.

Tangible or monetary benefits derived from IT project proposals, over their entire life cycle, are identified similarly to costs. Identifying these types of benefits will usually require an understanding of the work processes of the organisation. Moreover, many operational benefits are tangible and are more likely to display direct financial relationships. For example, monetary savings resulting from a web-based document management system could include reduced overhead costs. However, many IT-induced benefits are primarily strategic or tactical in nature and their financial rewards are difficult to predict [23]. These types of benefits can be handled by the non-monetary (intangible) element of the SelectIT module described next (see Fig. 2). 
To date, many researchers have focused on developing generic appraisal approaches, which can deal with all types of IT projects, in all circumstances [24]. This has resulted in the development and use of traditional appraisal techniques [20]. However, these appraisal techniques fail to accommodate the intangible benefits and risks associated with IT projects [25]. According to Farbey et al. [26], the IT project selection process should go beyond traditional 'business value' techniques and introduce concepts of value and risk $[10,19]$. To enable effective assessment of proposed IT projects, a number of intangible assessment criteria and associated sub-criteria need to be grouped into a structured hierarchy. This structured hierarchy will enable weighting of criteria and sub-criteria and evaluation of proposed IT projects against such sub-criteria.

\subsection{SelectIT Step 2: Define possibility distributions}

To cater for the inherent variability of an IT projects tangible cost and benefit and intangible value and risk estimates the possibility theory (i.e. fuzzy logic) approach was employed [27]. The first step to using possibility theory as a modelling tool is to define each IT project cost and benefit as a possibility distribution. The form of possibility distribution is determined by its membership function, $\mu(x)$. When the factor's value is possible, it has a membership value of one (1), and when its value is impossible, it has a membership value of zero (0). The factor can also have a possibility distribution between these units. For the purpose of the SelectIT module, it was assumed that the distributions will be one of the following types: (a) single value; (b) interval number; (c) triangular distribution; and (d) trapezoidal distribution. Stewart [5] and Mohamed and McCowan [28] provide full descriptions of these distribution types.

For each stage of the IT project life cycle, the organisation needs to estimate direct and indirect IT project costs. The organisation should set up a series of activity cost matrices for each stage of the IT project life cycle. This step allows the organisation to define the appropriate possibility distribution for each cost element in dollar values. These defined cost distributions for each activity need to be related to a particular year of the IT project life cycle to enable them to be discounted to present day. Completing this exercise for each activity over each year of the IT project life cycle will enable the creation of an annual cost matrix for 
proposed IT projects. Monetary IT project benefit possibility distributions are defined in a similar manner to IT project costs.

After identifying the relevant non-monetary criteria and sub-criteria for each IT project proposal (i.e. Step 1) the organisation can begin to define their possibility distributions using a predetermined qualitative scale (i.e. $0-10$ ). Value is defined as the predicted value added to the sub-criteria (factor) due to the implementation of the IT project. Risk is defined as the product of probability of the event and the associated severity (loss) e.g. high, medium and low severity. The determination of value and risk is based on available information on the proposed IT project. Since the SelectIT module relies on subjective assessment of value and risk factors, it is important that scores are based on reliable sources and judgement. A possibility based linguistic assessment scale was developed for this purpose with different fuzzy sets represented on the universal set $U=[0,10]$ for each linguistic response (e.g. low value $=[1,3,5]$ ). Readers are referred to Stewart [5] for a complete description of the designated linguistic scale and its' application. Using an appropriate 'value' and 'risk' assessment scale, the possibility distributions for each value and risk factor can be established.

\subsection{SelectIT Step 3: Develop resultant aggregated possibility distribution}

Applying the conventional time-cost-of-money principle, the Net Present Value (NPV) for all monetary factors can be calculated. The NPV approach is used to enable a direct comparison between tangible costs and benefits of proposed IT projects. To facilitate the arithmetic manipulation (addition and multiplication) of the possibility distributions, the vertex method [29] can be utilised. Also, the following three assumptions are made: monetary factors (prior to IT project implementation) take place in Year (0); monetary factors (during operation of the IT project) are converted to Year (0) i.e. negative cost outflow and positive benefits in-flow; and cash flow discount can be represented by any of the above four forms of possibility distribution. Costs and benefits must be grouped separately and signified by a negative and positive monetary value. Converting each cost back to a NPV will establish the aggregated cost possibility distribution for the proposed IT project. The aggregated benefits possibility distribution is obtained in the same manner. 
There are three major steps to establish the aggregated non-monetary possibility distribution. The first of these steps is to weight the value and risk factors using the AHP method [30]. The organisation must determine how value and risk contribute to the final goal to obtain the IT project(s) with the highest net benefit. The second step is to combine the weighted possibility distributions of value and risk factors using the Averaging Method (e.g. [28]). Then, the same method is used to combine the aggregated value and risk possibility distributions. All of these relatively complex calculations are undertaken by the SelectIT module of the ProjectIT software package presented later.

\subsection{SelectIT Step 4: Combine resultant aggregated possibility distribution}

This step is required to combine the resultant monetary and non-monetary possibility distributions for each proposal. Before this process can be undertaken, the resultant monetary possibility distributions for each IT project proposal must first be modified so that they have the same range and units. Thus, they are converted into their 'normalised' form. Non-monetary values are already on a scale from 0-10 and do not need to be normalised. However, monetary values have a \$ unit and a magnitude range that varies from IT project to project. Once the resultant monetary possibility distributions have been normalised, they can be combined with the resultant non-monetary possibility distribution to form a unified distribution. The Averaging Method is used to combine the monetary and non-monetary possibility distributions. The organisation must weight the resultant monetary and non-monetary possibility distributions to enable their combination. An organisation with a strategic outlook may assign the non-monetary (intangible) possibility distribution with high weighting. However, an organisation, which is focused on achieving tangible benefits from their IT investments, may assign the monetary (tangible) possibility distribution high weighting. Again, the SelectIT module of the ProjectIT software package handles these calculative processes.

\subsection{SelectIT Step 5: Rank IT project proposals}

The IT project proposals are ranked using the Ranking Index Method (e.g. [28]). Once the projects are ranked according to their index value, the organisation can select which project(s) will be implemented. Naturally, the number of projects selected will depend on the designated budget. Finally, the chief 
information officer may wish to make decisions directly from the resultant monetary and non-monetary possibility distributions reported by SelectIT.

\section{Strategic IT implementation and monitoring - ImplementIT}

Within most sectors of government and private industry there are suggestions that IT investments are often accompanied by poor vision and implementation approaches, insufficient planning and coordination and are rarely linked to business strategies [31-34]. The successful implementation of new and innovative IT requires the development of strategic implementation plans prior to IT project commencement [35]. Effective planning should go some way to reduce the current gap between output and expectation from IT investments [8]. Only recently, there has been growing interest in developing planning frameworks to aid IT implementation [33,36]. In an attempt to improve rates of effective IT diffusion the author developed a strategic IT implementation and monitoring framework (Fig. 3). This previously reported framework [11] includes a detailed step-by-step method which is supported by Gottschalk’s [37] ten predictors for effective IT implementation. A brief description of each step in the ImplementIT module of the ProjectIT framework is provided in the following sections. Readers are referred to Stewart et al. [11] for a comprehensive description of the ImplementIT framework and its' application for the implementation of a new Project Management Information System (PMIS) by a large multi-national infrastructure services organisation based in Australia. Finally, readers should note that the six steps are facilitated by the ImplementIT module of the ProjectIT software tool.

\section{(INSERT FIGURE 3)}

Fig. 3. Strategic IT implementation and monitoring module (ImplementIT)

\subsection{ImplementIT Step 1: SWOT factors}

Central to this step is the incorporation of the scale of values of the corporate management of the organisation (e.g. objectives, perceptions, beliefs and challenges). This activity is important because it defines the way the organisation is managed and the criteria under which strategies are evaluated. Keeping in 
mind the scale of values of the organisation's corporate management, the IT review committee needs to undertake an external and internal analysis (see below). The former examines the environment in which the organisation is participating to study the potential opportunities and threats whereas the latter identifies the weaknesses and strengths of the organisation. Combining the results of the external and internal analysis and taking into account the scale of values, the SWOT (Strengths, Weaknesses, Opportunities, and Threats) factors are identified. There is no standard list of factors that apply for all organisations because of the specificity of each set. However, strengths tend to relate to the competitive advantages and other distinguishing competencies, which can be exploited by the organisation on the market. Weaknesses are limitations which hinder the process of an organisation in a certain direction. Opportunities relate, for example, to the technology enabled advantages that can be obtained by the uptake of IT. Threats relate to an array of macroscopic and microscopic problems that exist or may arise which can potentially jeopardise the successful implementation of proposed IT projects.

\subsubsection{External environment analysis}

The changing business environment and increased IT capabilities are translating into more focused emphasis on strategic integration [36,38]. Increased global competition on one hand and availability of communication-tools on the other, have enhanced opportunities for organisations to establish joint ventures, partnering and long-term relationships with clients and/or suppliers. Therefore, the main purpose of this analysis is to identify IT-enabled integration and alliancing opportunities/threats. It is not sufficient though to concentrate the external analysis at the macroscopic level of the industry alone [35]. This is because even at the microscopic level of individual business divisions, IT spending has grown rapidly with operations and maintenance costs dominating the budget.

\subsubsection{Internal environment analysis}

Several researchers have articulated the need to consider how the internal organisational environment is determinant of the strategic IT implementation planning process [39]. For example, the organisation's corporate culture can facilitate its strategic IT planning by being congruent with it $[34,40]$. The 
organisation's planning and control style, is perhaps in part a function of corporate culture, similarly influences strategic IT implementation planning [41,42]. Likewise, organisational size, organisational structure (mechanistic vs. organic) and management style (entrepreneurial vs. conservative) may influence strategic IT implementation planning $[43,44]$. The primary role of the internal analysis is to identify the weaknesses and strengths of the organisation. By collating all the opportunities and threats obtained through external analysis, combined with strengths and weaknesses obtained through internal analysis the organisation can undertake SWOT analysis as explained below.

\subsection{ImplementIT Step 2: SWOT analysis}

Internal strengths and weaknesses, as well as external opportunities and threats obtained in step one form the foundation of SWOT analysis. However, merely pinpointing SWOT factors is too often only a superficial and imprecise listing or an incomplete qualitative examination of internal and external factors. This gives rise to the need of a more efficient use of SWOT as argued by McDonald [45]. The Analytical Hierarchy Process (AHP) is deemed the most appropriate analytical method for development of a hybrid method with SWOT. AHP is an effective tool in structuring and modelling multi-criteria problems and has been successfully used in a variety of applications [e.g. 11,46]. The idea in utilising AHP within a SWOT framework is to systematically evaluate SWOT factors and commensurate their intensities, adding value to SWOT analysis. This value can be achieved by pairwise comparison between SWOT factors and analysing them by means of the eigenvalue technique as applied in AHP. This offers a good basis for examining the present or anticipated situation more comprehensively. After carrying out these comparisons, decisionmakers will have quantitative information about the decision-making situation; for example, whether there is a specific weakness requiring all the attention, or if the organisation is expected to be faced with future threats exceeding the organisation's combined opportunities. Stewart et al. [11] report a case study detailing the use of the AHP/SWOT hybrid model for the weighting of strategic SWOT factors. 


\subsection{ImplementIT Step 3: IT diffusion strategy ‘story telling’}

To develop an effective IT diffusion strategy, the information sought and gathered in the previous step must be carefully analysed, and recommendations that result from this analysis must be reviewed by all that have a vested interest in those recommendations. One powerful tool for structuring this critical analysis is called 'story telling'. Proponents suggest that story telling forces planners to think through their recommendations and helps build support for the implementation efforts that are to follow [47]. The work of Goldratt [48], studied by both scholars and practitioners underscores the power of a story. Although fictional, and not purposely written as a strategic plan, The Goal [48] illustrates the heuristic power of a drama depicting human foibles in the pursuit of organisational excellence. This same heuristic power can be created when teams are brought together to plan for the integration of IT [8]. Story telling provides both a method and a forum for the team to think through the changes necessary to facilitate implementing the IT system and at the same time, address the resistance to change that might be encountered.

The story should clearly describe how the proposed project will benefit the organisation (tie-in to the organisations strategy and plans), how organisational assets and processes will be affected by the new IT project and what changes will be necessary to take full advantage of the IT project's capabilities (i.e. substitution, enhancement, transformation). Also, the story must convey not just proposals for changes in structure, people and tasks deemed necessary to make best use of the system, but the logic behind their recommendations. Story telling builds on external and internal factors examined in SWOT analysis by treating strategy as an evolving drama incorporating the most likely forces affecting the intended outcome of the story i.e. goal.

\subsection{ImplementIT Step 4: Operational strategy}

From the IT diffusion strategy, the operational strategy is derived. Stories formulated in the previous step are developed into a more detailed operational strategy, which considers each decision-making tier of an organisation. Development of an operational strategy corresponds to the codification i.e. the clarification and expression of strategies in terms sufficiently clear to render them formally operational. In developing an 
operational strategy, the chosen scenarios established by 'story telling' should be analysed in terms of functions (business systems), hierarchies and responsibilities (organisational structure), as well as in terms of the technical architecture required for the building of IT systems that would support the alternative growth strategies. Hence, in this step various models of the target organisation should be elaborated: a functional model depicting IT deployment; an organisational model depicting the responsibilities and hierarchies; and a technical model depicting IT specifications i.e. network requirements, software and hardware requirements, security, etc. Gottschalk [49] confirms that a well-documented operational plan is essential for successful IT implementation, especially those plans which clearly outline IT project responsibilities.

\subsection{ImplementIT Step 5: Implementation strategy 'action plans’}

The implementation strategy is the most detailed component of the proposed strategic IT implementation framework. This step requires the definition of robust actions, the evaluation of budgetary requirements, the study of time and organisational constraints, the elaboration of human resource issues, management and plan coordination, migration and diffusion etc. In addition, the action plans need to be examined concerning its risks, strategic importance and harmonised integration within the overall evolution of the specific organisation. There are three main stages to the development of the implementation strategy: (1) definition of action plan elements; (2) elaboration of action plan; and (3) risk mitigation and coping strategies.

\subsection{ImplementIT Step 6: Monitoring plan}

Developing a strategic implementation plan for IT projects does not guarantee their successful implementation. Consideration should be given to the continual performance monitoring of the implemented IT project over its' life cycle. The IT monitoring plan should consider performance measures and data collection strategies required for each IT project implemented by the organisation. Applying the measurement concept is not always straightforward. To assess IT-induced performance improvement, one must select an easily definable and limited number of performance measures with a mix of short and longterm goals. The developed monitoring plan should include the plan for collecting essential IT performance indicators which can be utilised in the EvaluateIT phase the IT project life cycle. 


\section{IT performance evaluation - EvaluateIT}

Generally, IT investment appraisal is more difficult than other investment decisions because IT-induced benefits are hard to identify and quantify [3,7]. The IT productivity paradox prompted calls for new approaches to evaluate IT-related investments $[3,8,50]$. In an attempt to provide a balanced approach to IT performance evaluation, the author recently developed and empirically validated an IT performance evaluation framework, in the form of an IT Balanced Scorecard (BSC) [5,7,9,12-14]. This IT BSC forms the foundations of the EvaluateIT five-step module of the ProjectIT framework and incorporates five (5) robust IT-related performance measurement perspectives (see Fig. 4):

- Operational Perspective: This perspective is mainly concerned with the integration of IT into the organisation and the role it plays in process coordination and integration between the organisation and its counterparts. The measurement and evaluation of the newly coordinated/integrated processes should yield useful data about the impact IT has on the productivity and efficiency of these processes.

- Benefits Perspective: The generic term 'benefits' goes beyond traditional financial measures (i.e. NPV, ROI, IRR) to encompass the many non-monetary or intangible benefits derived by IT implementation. This perspective investigates the link between IT implementation and associated tangible and intangible benefits experienced by the organisation. Tangible benefits might include time and cost savings, which are relatively easy to assess/measure. However, intangible benefits are more difficult to measure and typically include non-monetary elements [51].

- User Orientation Perspective: From the user's perspective, the value of an IT system/tool is based largely on the extent to which it helps the user do the job more efficiently and effectively. This perspective covers issues such as tool utilisation rate, availability of training and technical support and satisfaction with the system/tool. New IT applications, not embraced by the user, will obviously fail to provide value to the organisation. 
- Strategic Competitiveness Perspective: This perspective differs from the 'benefits' perspective by focusing on the long-term strategic goals of the organisation and how the newly implemented IT creates competitive advantage in the future e.g. potential for global cooperation, enhancing organisational image, and attracting more sophisticated clients (see Fig. 4). This perspective is perhaps the most difficult to quantify but has the greatest potential in the information era.

- Technology/System Perspective: This perspective refers to the technical system (i.e. hardware and software). This perspective is at the centre of the BSC framework since the remaining four perspectives are expected to relate to the performance of the technology/system itself (Fig. 4). This perspective covers issues relating to the technology/systems reliability, security and suitability to the application/process (see Fig. 4).

\section{(INSERT FIGURE 4)}

Fig. 4. Information technology balanced scorecard

Fig. 5 illustrates the process for evaluating IT performance improvement utilising the EvaluateIT five-step procedure: Step 1: develop IT performance measures; Step 2: establish weights; Step 3: apply IT performance measures; Step 4: develop utility functions for each IT performance measurement; and Step 5: evaluate overall IT performance improvement. A brief description of each step is provided in the following sections. The reader is referred to Stewart and Mohamed [9] for a full description of the IT performance evaluation process and subsequent studies [7,12-14] for its empirical validation as well as application in an industry setting. Again, these five steps are facilitated by the EvaluateIT module wizard of the ProjectIT software package.

\section{(INSERT FIGURE 5)}

Fig. 5. IT performance evaluation module (EvaluateIT) 


\subsection{EvaluateIT Step 1: Develop IT performance measures}

From the ImplementIT module (Step 6: monitoring plan) a variety of quantitative and qualitative measures would have been identified, which capture accurate and timely data reflecting the full potential benefits of the portfolio of implemented IT systems/tools. For each identified measure, data can be manually or automatically collected through various means, including, questionnaires, interviews, records and databases. This step needs to be repeated for each IT BSC perspective described previously. Upon completion of this exercise, developed perspectives, indicators and measures can be weighted (Step 2).

\subsection{EvaluateIT Step 2: Establish weights}

Consistent with assigning weights in the SelectIT and ImplementIT modules of the IT BSC the AHP [30] was the recommended approach to facilitate weighting perspectives, indicators and measures. To establish the relative weights, expert judgement is required to compare the relative importance of each perspective, indicator and measure using the fundamental scale developed by Saaty [30] (i.e. $1=$ equal importance to $9=$ absolute importance). Global weights can be obtained by multiplying the relative weight of a performance measure by the relative weights of its parent indicator and perspective. These global weights are used for evaluating the overall IT performance improvement, as described in Steps 3 to 5.

\subsection{EvaluateIT Step 3: Apply IT performance measures}

Each IT performance indicator may have one or more associated measures. These measures have their own metrics, data sources and minimum and maximum performance targets, as predetermined by top management. To effectively handle all this information, a measurement description card for individual measures must be completed. Repeating this step for other measures gives rise to a collection of diverse performance results, at a certain point in time. To enable the proper assessment of these results, measures must relate to commensurable units (utiles). This process allows the aggregation of measurement results into a single value reflecting the degree of derived IT-induced performance improvement at a particular point in 
time. Thus, the problem of measuring IT performance improvement was, therefore, reduced to a multiattribute problem. As a result, the approach chosen to handle this problem was the construction of a multiattribute utility model, based on the combination of weighted one-dimensional utility functions, according to expected utility theory. This process is explained further in the following step (Step 4).

\subsection{EvaluateIT Step 4: Develop utility functions for each IT performance measurement}

Multi-Attribute Utility Theory (MAUT) takes into consideration the decision-maker's preferences in the form of a utility function which is defined over a set of criteria [52]. MAUT generally combines the main advantages of simple scoring techniques and optimisation models [53]. Utility is a measure of the desirability or satisfaction and provides a uniform scale to compare and/or combine tangible and intangible criteria [54], whereas a utility function is a device which quantifies the preferences of the decision-maker by assigning a numerical index to the varying levels of satisfaction of a criterion [55]. In order to determine the overall utility function for any criterion, a decision-maker needs only to determine $N$ one-dimensional utility functions for that criterion, where $N$ is the number of attributes associated with this criterion. For the purpose of the EvaluateIT module, the utility function is developed from the decision-makers preference of values assigned between the worst outcome (i.e. baseline performance target $=$ a utility value of zero) and the best outcome (i.e. optimum performance target $=$ a utility value of 100). This establishes the range of utility values from 0 to 100, between the worst and the best possible outcomes. The more utility values obtained between these two limits, the more accurate and reflective is the utility curve and associated function. Once the utility function is created the measure targets for any value between the baseline and optimum performance target can be determined. This process can be utilised for each measure developed across the five IT BSC perspectives. Finally, readers should note that MAUT is a qualitative approach that is subject to human judgement. To overcome such human bias, the AHP could be applied to this step. AHP can improve the reliability of utility functions since it can measure the degree to which judgements are inconsistent and establishes an acceptable tolerance level for the degree of inconsistency. 
Substituting actual measurement results into their respective utility function gives rise to the equivalent utility values. Multiplying these values by their corresponding global weight (obtained in Step 2), generates weighted utility values. Since the global weights must add to unity, the overall IT performance improvement can be simply obtained by summation of the weighted utility values. It is worth pointing out that the user has the freedom to evaluate IT-induced performance improvements at one or more different levels of the EvaluateIT framework hierarchy (i.e. for any particular indicator or perspective). Finally, it should be noted that the ImplementIT module of the ProjectIT software package handles these calculative requirements.

\section{ProjectIT software package development}

Currently, the author is developing an IT project life cycle management software package (ProjectIT) based on the architecture briefly described above. Since the intention was to develop a standalone windows based application the software was developed in Microsoft Visual Studio using C++ language. The primary objective of the software tool is to provide organisations with a structured but user-friendly means to effectively select (SelectIT), strategically implement (ImplementIT) and comprehensively evaluate (EvaluateIT) the performance of their portfolio of IT projects. The software package includes procedure wizards which support the above-mentioned module steps and undertakes the necessary analytical processes. However, these wizards are by no means rigid in design and the user is provided with plenty of scope to adapt framework templates and individual elements to suit their specific organisational requirements and objectives. Undoubtedly, ProjectIT needs to be sufficiently flexible in form to constantly encompass the dynamic nature of IT projects and changing organisational goals. Additionally, the proposed ProjectIT framework will be supplemented by a web-based guidebook detailing illustrative examples and include an extensive reporting function that can be used by management to guide decision-making. Fig. 6 shows two illustrative screen shots of the ProjectIT software package. 
(INSERT FIGURE 6)

Fig. 6. ProjectIT software package

\section{Summary}

Organisations are investing substantial funds into IT in an attempt to transform or re-engineer traditional business processes and ultimately improve productivity and profitability. Adopting the IT project life cycle management approach, proposed herein, is the first step to ensure such transformations achieve desired objectives within time, cost and quality requirements. The described ProjectIT framework and associated modules for IT project selection (SelectIT), strategic IT implementation (ImplementIT) and IT performance evaluation (EvaluateIT) is one of the first comprehensive approaches to systematically and continuously manage IT projects. Such a framework would alleviate IT project risks, increase cost-benefit ratios and ensure that improved rates of diffusion occur. Currently the author is focused on further developing and testing the presented ProjectIT software package. Future research aims to further refine the architecture of each module of the ProjectIT framework, utilising a method of expert review and case studies, conducted across a diverse range of industry sectors. Ultimately, a commercially available ProjectIT software package will be made available.

\section{References}

[1] De Reyck B, Grushka-Cockayne Y, Lockett M, Calderini SR, Moura M, Sloper A. The impact of project portfolio management on information technology projects. International Journal of Project Management 2005;23:524-537.

[2] Love PED, Irani Z, Edwards DJ. Researching the investment of information technology in construction: An examination of evaluation practices. Automation in Construction 2005;14:569-582. 
[3] Gunasekaran A, Ngai EWT, McGaughey RE. Information technology and systems justification: a review for research and applications. European Journal of Operational Research 2006;173:957-983.

[4] Irani Z, Love PED. The propagation of technology management taxonomies for evaluating investments in information systems. Journal of Management Information Systems 2001;17(3):161-177.

[5] Stewart, RA. Life cycle management of information technology projects in construction. PhD Dissertation: Griffith University; 2003.

[6] Irani Z, Love PED. Developing a frame of reference for exante IT/IS investment evaluation. European Journal of Information Systems 2002;11(1):74-82.

[7] Stewart RA, Mohamed S. Evaluating the value IT adds to the process of project information management in construction. Journal of Automation in Construction 2003;12:407-417.

[8] Dos Santos BL, Sussman L. Improving the return on IT investment: the productivity paradox. International Journal of Information Management 2000;20:429-440.

[9] Stewart RA. Mohamed S. Utilizing the balanced scorecard for IT/IS performance evaluation in construction. Journal of Construction Innovation 2001;1(3):147-163.

[10] Stewart RA, Mohamed S. IT/IS projects selection using multi-criteria utility theory. Logistics Information Management 2002;15(4):254-270.

[11] Stewart RA, Mohamed S, Daet R. Strategic implementation of IT/IS projects in construction: a case study. Automation in Construction 2002;11(6):681-694.

[12] Mohamed S, Stewart RA. An empirical investigation of users' perceptions of web-based communication on a construction project. Automation in Construction 2003;12(1):43-53. 
[13] Stewart RA, Mohamed S. Evaluating web-based project information management in construction: capturing the long-term value creation process. Automation in Construction 2004;13(4):469-479.

[14] Stewart RA. IT enhanced project information management in construction: pathways to improved performance and strategic competitiveness. Automation in Construction 2007;16(4):511-517.

[15] Whittaker B. What went wrong? Unsuccessful information technology projects. Information Management \& Computer Security 1999;7(1):23-29.

[16] Kutsch E, Hall M. Intervening conditions on the management of project risk: dealing with uncertainty in information technology projects. International Journal of Project Management 2005;23:591-599.

[17] Jung Y, Gibson GE. Planning for computer integrated construction. Journal of Computing in Civil Engineering 1999:13(4):217-225.

[18] Irani Z, Sharif AM, Love PED. Transforming failure into success through organisational learning: an analysis of a manufacturing information system. European Journal of Information Systems 2001;10:5566.

[19] Stewart RA, Mohamed S. Balancing risk and value in IT projects selection. Journal of Building and Construction Management 2002;7(1):9-14.

[20] Klapka J, Pinos P. Decision support system for multicriterial R\&D and information systems projects selection. European Journal of Operational Research 2002;140(2):434-446.

[21] Osman K, Cengiz K, Basar O, Mehmet T. Multi-attribute information technology project selection using fuzzy axiomatic design. Journal of Enterprise Information Management 2005;18(3):275-288. 
[22] Wheatley M. Hidden costs of the humble PC. Management Today 1997; January:52-54.

[23] Ordoobadi SM, Mulvaney NJ. Development of a justification tool for advanced manufacturing technologies: system-wide benefits value analysis. Journal of Engineering and Technology Management 2001;18:157-184.

[24] Sharif AM, Irani Z. Research note: theoretical optimisation of IT/IS investments. Logistics Information Management 1999;12(1/2):189-196.

[25] Baccarini D, Salm G, Love PED. Management of risks in information technology projects. Industrial Management \& Data Systems 2004;104(4):286-295.

[26] Farbey B, Land FF, Targett D. Evaluating investments in IT. Journal of Information Technology 1992;7:109-122.

[27] Zhang GP, Keil M, Rai A, Mann J. Predicting information technology project escalation: a neural network approach. European Journal of Operational Research 2003;146:115-129.

[28] Mohamed S, McCowan AK. Modelling project investment decisions under uncertainty using possibility theory. International Journal of Project Management 2001;19:231-241.

[29] Dong W, Chiang W, Wong F. Propagation of uncertainties in deterministic models. Computers and Structures 1987;26(3):415-423.

[30] Saaty TL. How to make a decision: the analytic hierarchy process. European Journal of Operational Research 1990;48:9-26.

[31] Guida G. and Tasso C. Design and development of knowledge-based systems: from life cycle to development methodology. Chichester, UK: John Wiley and Sons, 1994. 
[32] Betts M. Strategic management of IT in construction. Oxford: Blackwell Science; 1999.

[33] Peansupap V, Walker DHT. Innovation diffusion at the implementation stage of a construction project: a case study of information communication technology. Construction Management and Economics 2006;24:321-332

[34] Raz, O. Goldberg A. How to make IT work: cognitive perspectives for better information technologies performance. European Management Journal 2006;24(2-3):199-205.

[35] Pena-Mora F, Vadhavkar S, Perkins E, Weber T. Information technology planning framework for largescale projects. Journal of Computing in Civil Engineering 1999;October:226-237.

[36] Fink D. Guidelines for the successful adoption of information technology in small and medium enterprises. International Journal of Information Management 1998;18(4):243-253.

[37] Gottschalk P. Implementation of formal plans: the case of information technology strategy. Long Range Planning 1999;32(3):362-372.

[38] Ahmad IU, Russell JS, Abou-Zeid A. Information Technology (IT), and integration in the construction industry. Construction Management and Economics 1995;13:163-171.

[39] Linderoth HCJ, Giuseppina P. Frames and inscriptions: tracing a way to understand IT-dependent change projects. International Journal of Project Management 2005;23:415-420.

[40] Applegate LM, McFarlan FW, McKenney JL. Corporate information systems management: text and cases. Homewood; Irwin: 1996. 
[41] Earl MJ. Integrating IS and the organisation: a framework of organisational fit. In: Earl MJ. editor. Information management: the organisational dimension. Oxford: Oxford University Press; 1996, p. 485502.

[42] Wang E, Chou H-W, Jiang J. The impacts of charismatic leadership style on team cohesiveness and overall performance during ERP implementation. International Journal of Project Management 2005;23:173-180.

[43] Doukidis GI, Mylonopoulos NA, Lybereas P. Information systems planning with medium environments: A critique of information systems growth models. International Transactions in Operational Research 1994;1(3):293-303.

[44] Thite M. Leadership styles in information technology projects. International Journal of Project Management 2000;18:235-241.

[45] McDonald MHB. The marketing planner. Oxford: Butterworth-Heinemann; 1993.

[46] Mahdi IM, Alreshaid K. Decision support system for selecting the proper project delivery method using analytical hierarchy process (AHP). International Journal of Project Management 2005;23:564-572.

[47] Shaw G, Brown R, Bromiley P. Strategic stories: How 3M is rewriting business planning. Harvard Business Review 1998;76(3):41-50.

[48] Goldratt E. The Goal. Great Barrington: North River Press; 1992.

[49] Gottschalk P. Descriptions of responsibility for implementation: a content analysis of strategic information systems/technology planning documents. Technological Forecasting \& Social Change 2001;68:207-221. 
[50] Milis K, Mercken R. The use of the balanced scorecard for the evaluation of Information and communication technology projects. International Journal of Project Management 2004;22:87-97

[51] Serafeimedis V, Smithson S. Information systems evaluation in practice: a case study of organisational change. Journal of Information Technology 2000;15(2):93-106.

[52] Goicoechea A, Hansen D, Duckstein L. Multi-objective decision analysis with engineering and business applications. New York: Wiley; 1982.

[53] Hatush Z, Skitmore M. Contractor selection using multi-criteria utility theory: an additive model. Building and Environment 1998;33(2-3):105-115.

[54] Ang AHS, Tang WH. Probability concepts in engineering planning and design - decision, risk and reliability. New York: John Wiley; 1984.

[55] Mustafa MA, Ryan TC. Decision support for bid evaluation. Project Management 1990; 8(4):230-235. 


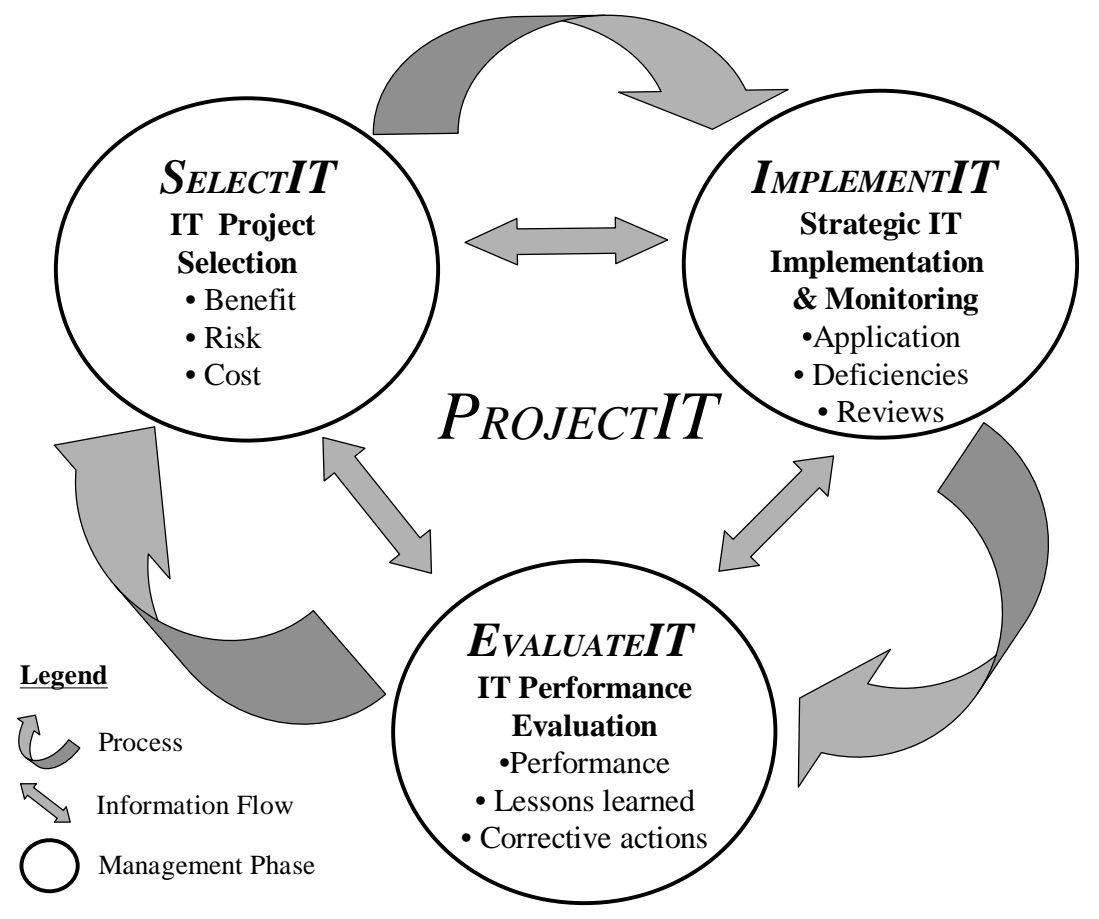

Fig. 1. IT project life cycle management process (ProjectIT) 


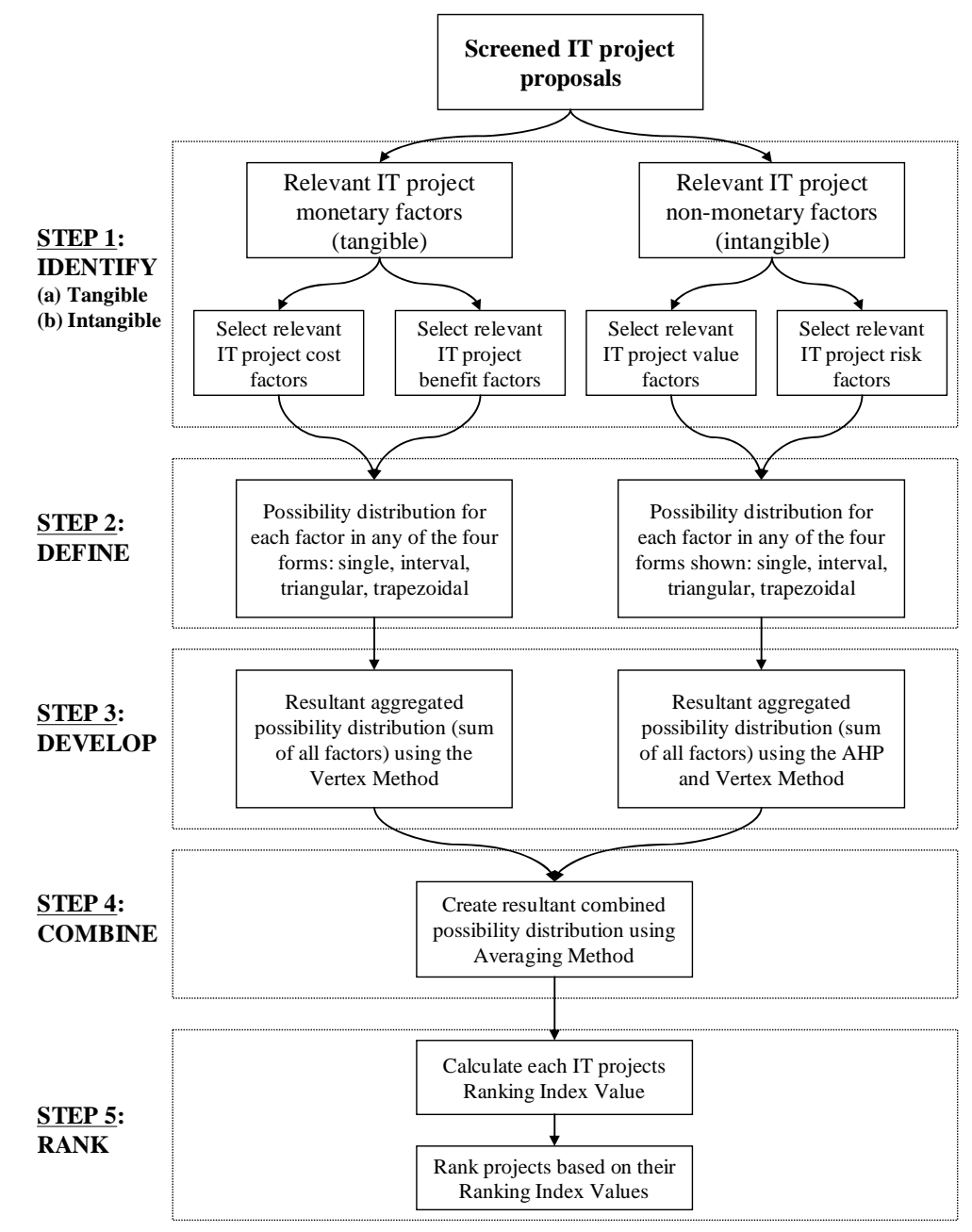

Fig. 2. IT project selection module (SelectIT) 
PROCESS

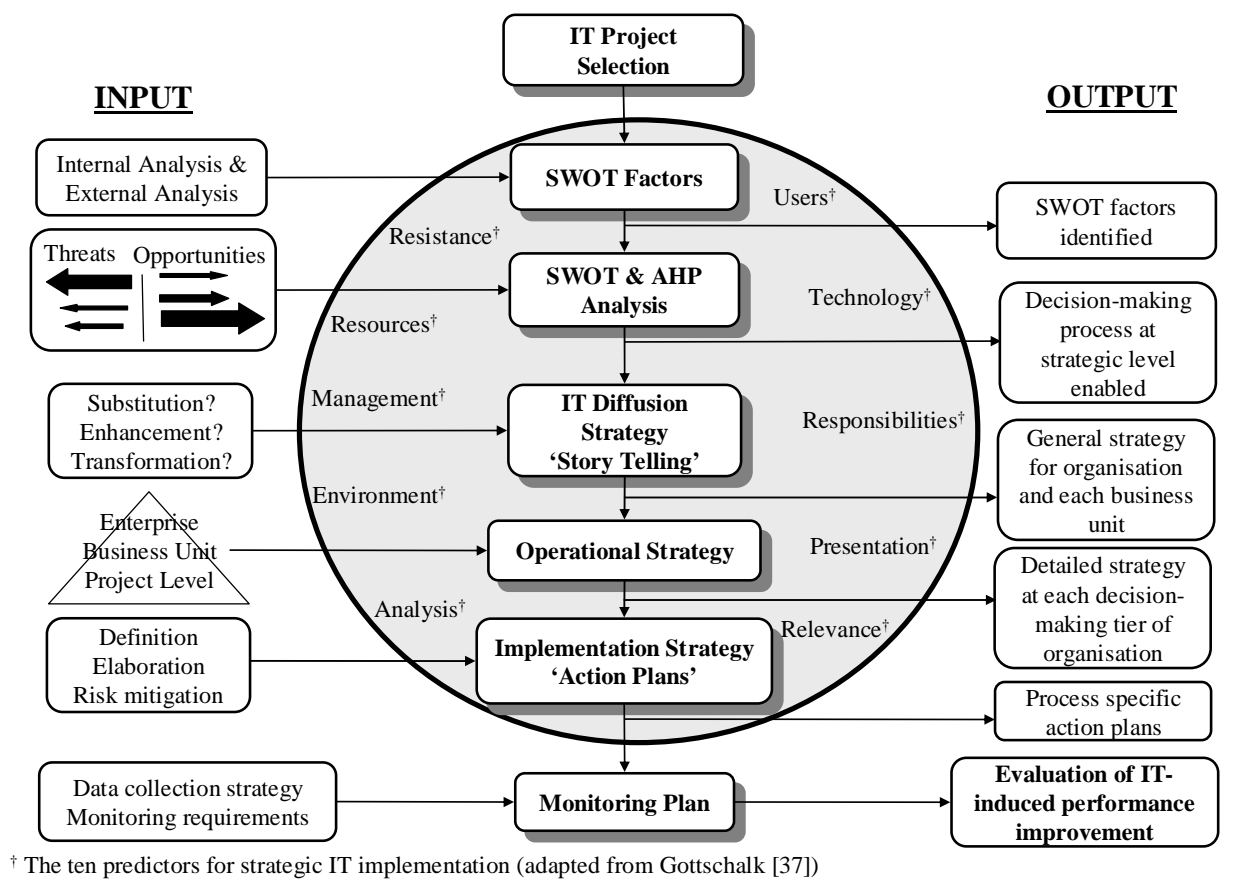

Fig. 3. Strategic IT implementation and monitoring module (ImplementIT) 


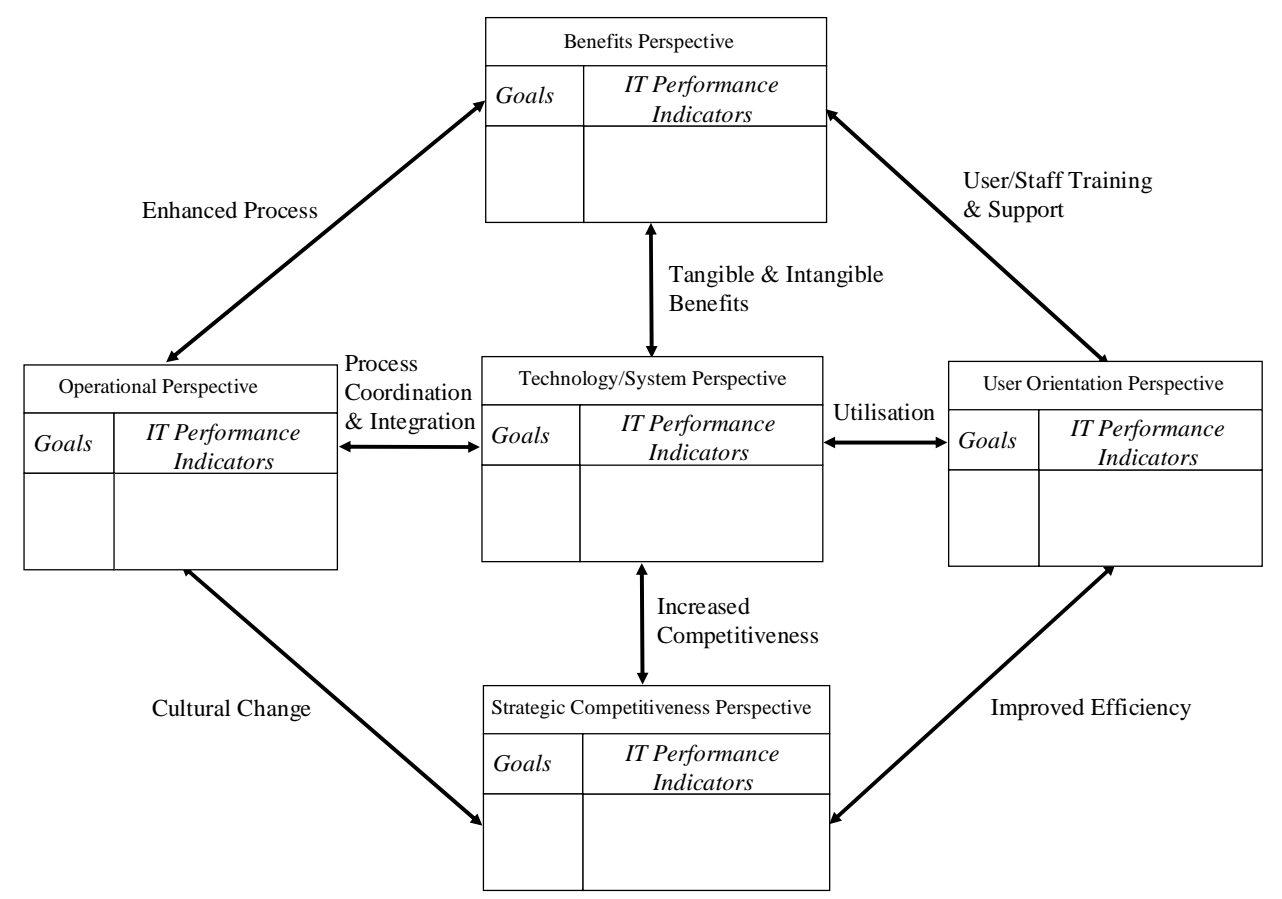

Fig. 4. Information technology balanced scorecard 


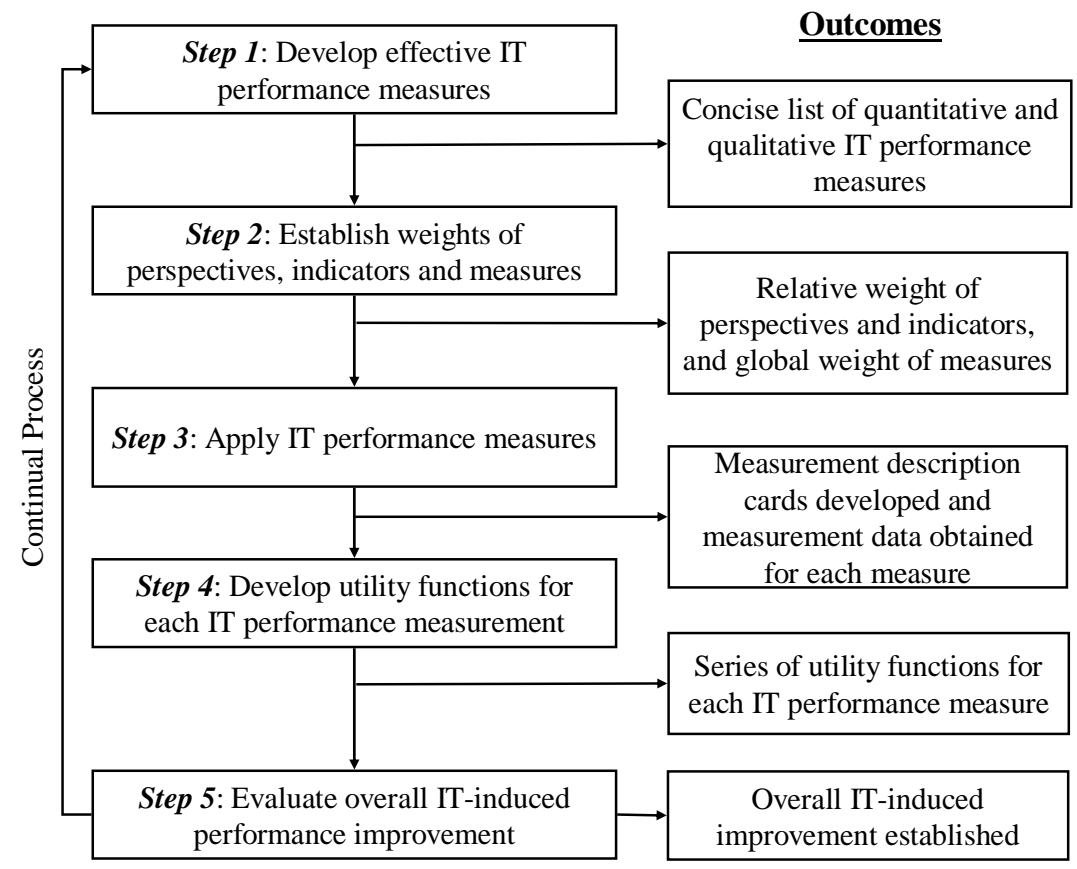

Fig. 5. IT performance evaluation module (EvaluateIT) 


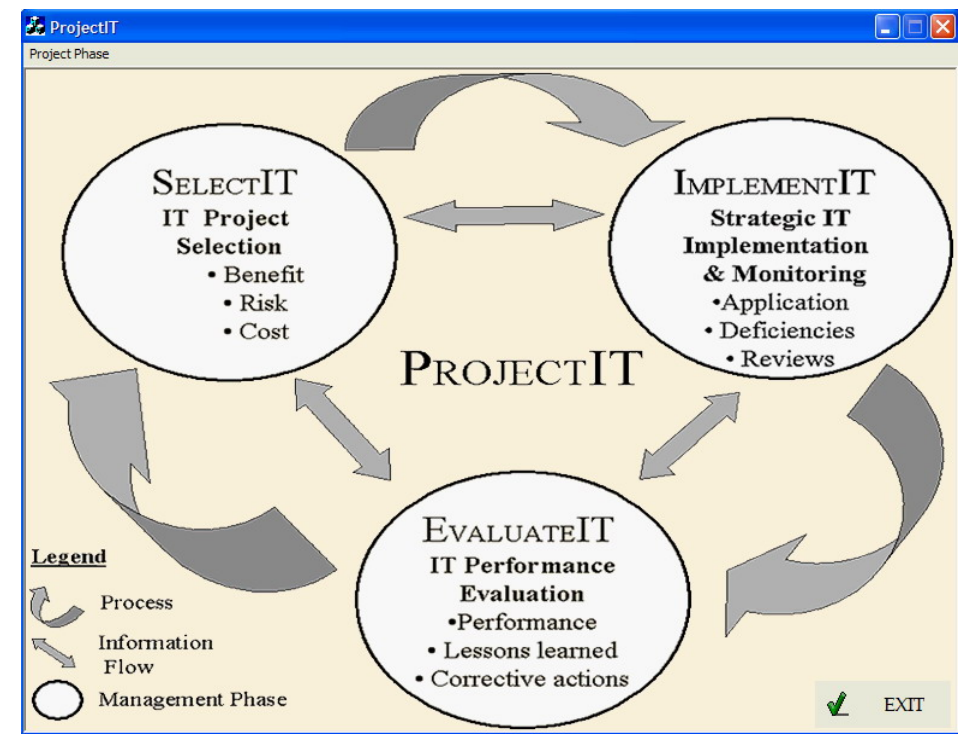

(a) ProjectIT introduction - select a phase of the IT project life cycle

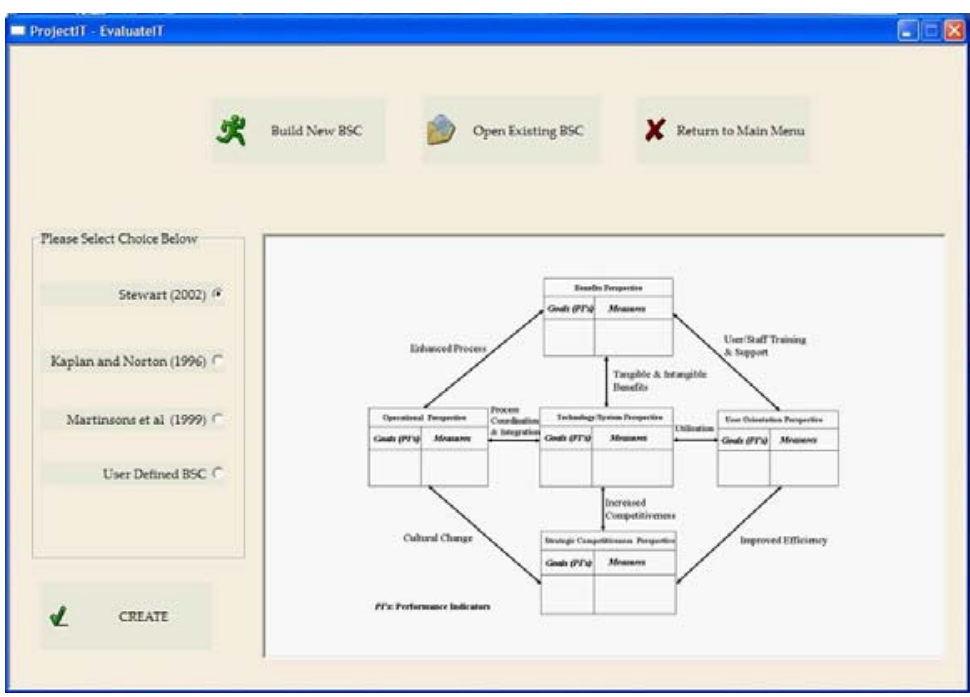

(b) EvaluateIT introduction - select an existing or user-defined BSC

Fig. 6. ProjectIT software package 